Kalpa Publications in Engineering
Volume 1, 2017, Pages 75-80
$\begin{aligned} & \text { ICRISET2017. International Conference on Re- } \\ & \text { search and Innovations in Science, Engineering } \\ & \text { \&Technology. Selected Papers in Engineering }\end{aligned}$

\title{
Three Phase Power Transformer Modeling Using FEM for Accurate Prediction of Core and Winding Loss
}

\author{
Sweta A Jain ${ }^{1}$ and Dr. Akshay A Pandya ${ }^{2}$ \\ ${ }^{1}$ M.Tech (Electrical Engineering),B.V.M Engineering College, Vallabh Vidyanagar, India \\ ${ }^{2}$ Associate Professor, B.V.M Engineering College, Vallabh Vidyanagar, India \\ swetajain217@gmail.com, aap.bvm@gmail.com
}

\begin{abstract}
This paper presents the modeling and analysis of core loss and winding loss in a power transformer. 2-D FEM and 3-D FEM are used for the accurate calculation of flux density distribution and total core and winding loss of a three phase $15 \mathrm{MVA}, 66 / 11 \mathrm{KV}$ power transformer. Finite element method (FEM) is a very powerful tool for transformer design and analysis; it takes into account the non-linear behavior of the core. Also the comparison of 2-D FEM and 3-D FEM is shown. The results of the proposed numerical method are compared with the experimental results (performed at Atlanta Electricals Pvt. Ltd.).
\end{abstract}

\section{Introduction}

By far, the transformer is the electrical machine with highest efficiency. However, in order to become more competitive in market producers want to achieve even higher efficiency of the transformer. As a result at this stage it is very important to calculate the performance of the transformer as accurately as possible. A transformer is an important link between the point of power generation and points of electric power utilization. Without transformer it would not be possible to use the electric power in different ways as it is used today. Thus the need to accurately estimate the losses of the transformer is increasing day by day.

Core loss of the transformer comprises of hysteresis loss and eddy current loss. As both of these losses depend on constant value $\mathrm{K}$, magnetic field density $\mathrm{B}$ and supply frequency $f$ which are constant for a transformer, so the core loss of the transformer is also constant and do not vary with the load. Because of availability of better core material the core loss in the recent years is much lower than the past decades, however in order to improve the transformer performance in the design stage, the information such as localized flux density distribution and transformer losses is needed[1]. The magnetic field analysis and iron loss estimation in the laminated core is important for electromagnetic devices[2].As the load current in the transformer increases, load losses, namely 
winding loss and stray loss also increases. In order to improve the transformer performance at the design stage it is important to know the flux density distribution.

In this paper, the finite- element method (FEM) is used to accurately determine the losses of 15 MVA power transformer. A 3-D model of power transformer is considered to analyze the flux density in the core and losses. Similar transformer was also modeled in 2-D in order to compare the accuracy of results in both the model. Also the results of both the model are validated with the experimental results.

\section{Finite element method(FEM)}

Finite element method is a numerical technique for finding approximate solutions to boundary value problem. FEM can be used for solving differential equations in many disciplines like, electromagnetics, magneto statics, thermal conduction, structural mechanics, transient, fluid dynamics and acoustic[3]. The basic idea is to subdivide a large problem into smaller, simpler parts that are called finite elements or mesh.

The key advantage of FEM over other numerical technique is that it can incorporate non-linear, anisotropic, and non-uniform media into a solution scheme. The formulation is independent of the geometrical complexity. FEM can also be used in solving problems which involve coupling of electromagnetic fields with circuit or other physical fields. FEM is available in various commercial softwares. Figure 1 explains the flowchart of the algorithm for finite element analysis of transformer[4]

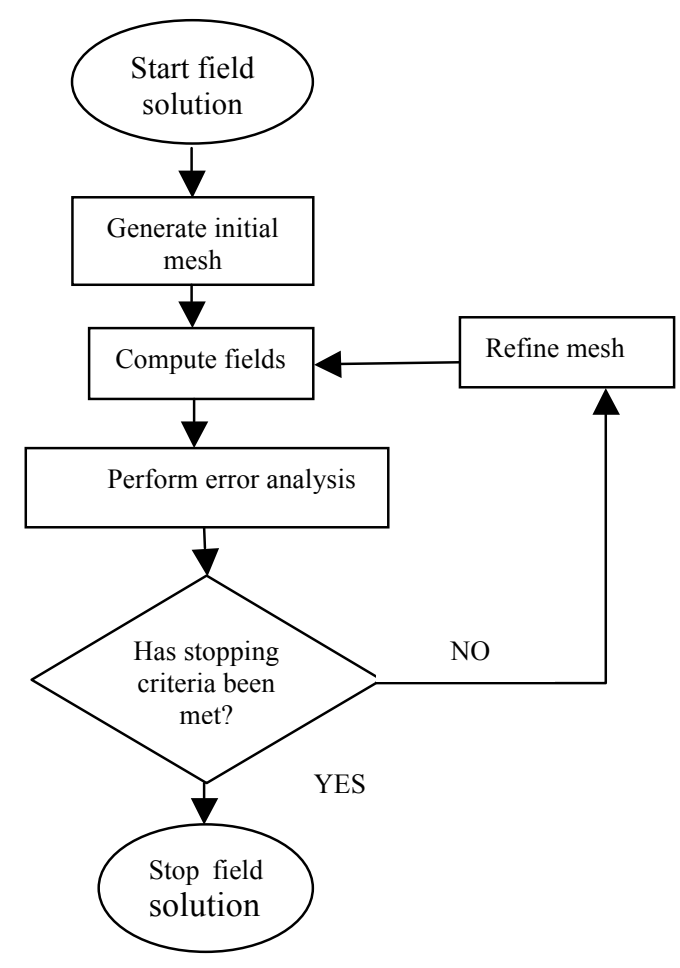

Figure1: flowchart for algorithm of FEM 


\section{Modeling of power transformer in 3-D}

A three phase, 15 MVA power transformer is simulated using 3-D FEM as shown in Figure 2. The transient solution is used for the computation of results.

The core and windings are made up of CRGO silicon steel and copper respectively. LV windings are simulated in order to calculate the core loss and magnetic field density in the core of power transformer. Figure 3 shows the mesh model of power transformer. Mesh model consist of dividing the model into a small number of triangles in 2-D model and tetrahedron in case of 3-D model.

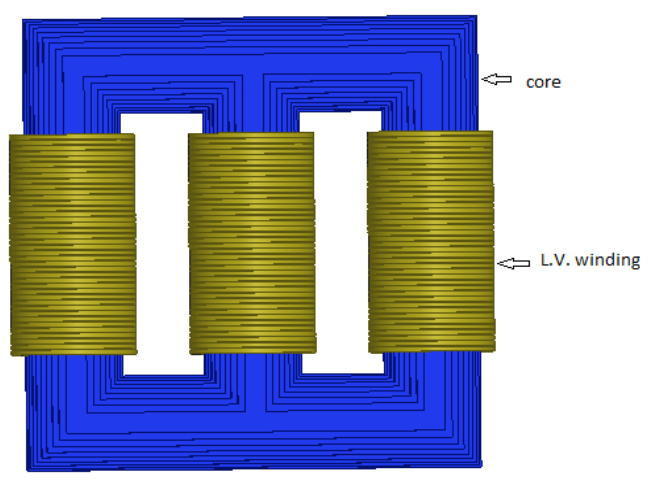

Figure 2: 3-D model of 15 MVA power transformer.

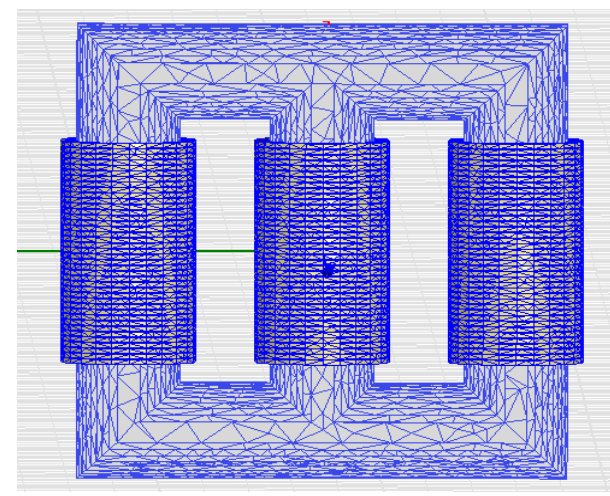

Figure 3: Mesh model of 15 MVA power transformer.

\subsection{Analysis of core loss and magnetic field density}

Figure 4 and Figure 5 shows the peak voltage of LV winding and magnetizing current waveforms of $15 \mathrm{MVA}, 66 / 11 \mathrm{KV}$ power transformer respectively. The excitation is given in each phase by the phase shift of 120 degree. The LV of the transformer is star connected, so the per phase rms voltage of $\mathrm{LV}$ winding is $6.35 \mathrm{KV}$ and the obtained value of peak voltage of LV winding is $8.92 \mathrm{KV}$. The obtained value of magnetizing current is $0.4349 \mathrm{~A}$.

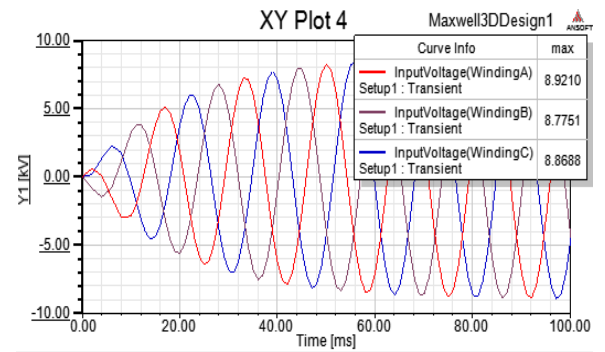

Figure 4: LV winding peak voltage waveform of 15 MVA power transformer.

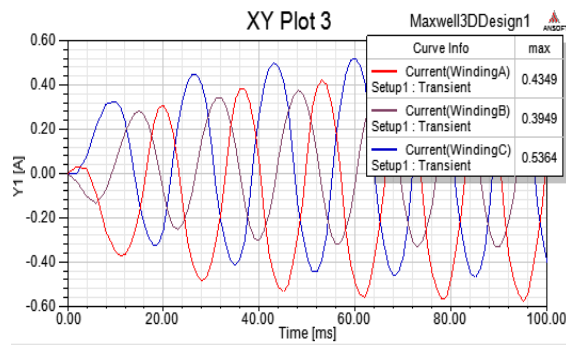

Figure 5: Magnetizing current waveform of 15 MVA power transformer.

Figure 6 shows the magnetic field distribution in the core of power transformer. It can be seen that the magnetic field density is more prominent on the corner of the core. This is due to the fact that 
losses at the corner are more, as the flux lines turns at an angle from limb towards the yoke leading to higher losses in this area.

Figure 7 shows the plot of core loss $\mathrm{v} / \mathrm{s}$ time. Core loss is the no load loss it does not changes with the load. So the core loss can be computed by simulating the LV windings only. It can be seen that the core loss becomes stable within five cycles (as transient analysis is performed). The obtained value of core loss is $9.2052 \mathrm{KW}$

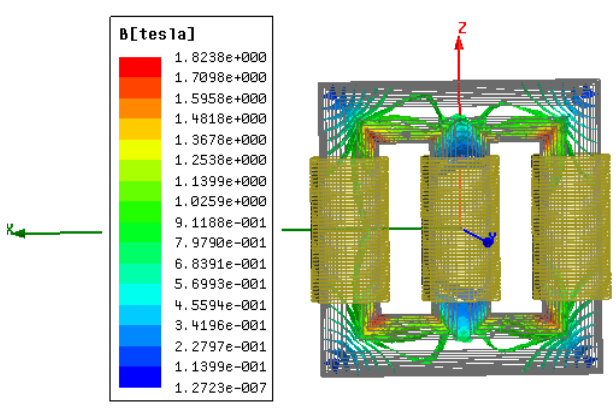

Figure 6: Magnetic field distribution in the core

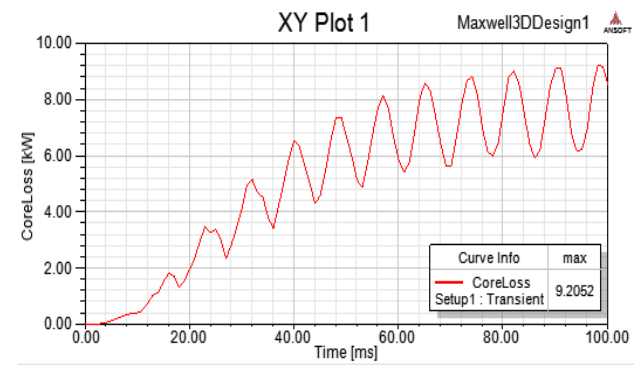

Figure 7: Core loss graph of 15 MVA power transformer

Further, modeling of transformer was done with H.V. winding to analyze the winding loss. Figure. 8 shows the winding loss of the transformer in watts/meter cube is 3632 . The volume of winding is 16.42 meter cube (calculation is not shown in the paper). Multiplying them gives the winding loss of transformer which is 59637.44 watts.

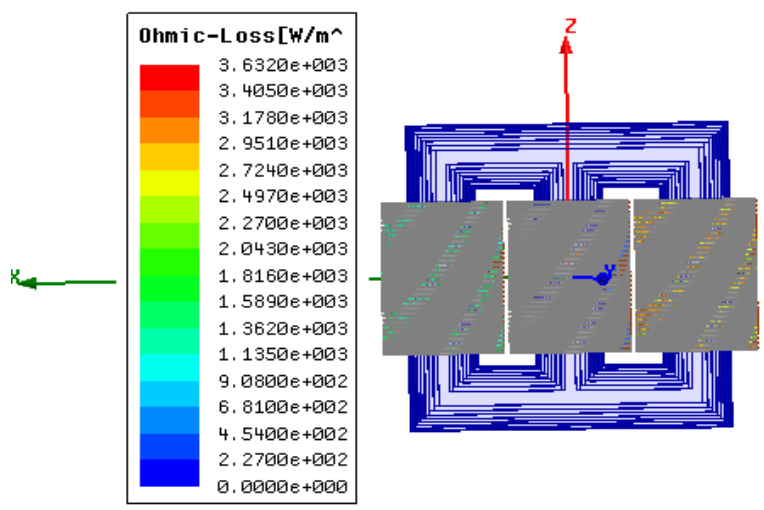

Figure 8: ohmic loss of winding (watts/meter cube)

As we have considered the transient solution, the value of winding loss changes with the time in different parts. So we have taken the maximum value of winding loss here

\subsection{Comparison of results with experimental values}

Comparison was done in order to determine the accuracy of the proposed method 
Table 1 shows the comparison of obtained results with experimental values and their $\%$ variation.

\begin{tabular}{|c|c|c|c|}
\hline PARAMETERS & $\begin{array}{c}\text { EXPERIMENTAL } \\
\text { RESULTS }\end{array}$ & $\begin{array}{c}\text { RESULTS } \\
\text { OF 3-D } \\
\text { FEM }\end{array}$ & $\begin{array}{c}\% \\
\text { VARIATION } \\
\text { FROM EXP. } \\
\text { RESULTS }\end{array}$ \\
\hline CORE LOSS & $9034 \mathrm{~W}$ & $9205.2 \mathrm{~W}$ & $1.9 \%$ \\
\hline OHMIC LOSS & $57988 \mathrm{~W}$ & $59637 \mathrm{~W}$ & $2.8 \%$ \\
\hline
\end{tabular}

Table 1: comparison of results

\section{Modeling of power transformer in 2-D}

The same three phase three legged 15 MVA power transformer was modeled using 2-D FEM in order to calculate the core loss. FIG.9 shows the 2-D model of 15 MVA power transformer. The LV winding was simulated in order to calculate the core loss of the transformer. FIG.10 shows the LV winding peak voltage waveform of 15 MVA power transformer. The peak voltage of LV winding is $8.868 \mathrm{KV}$

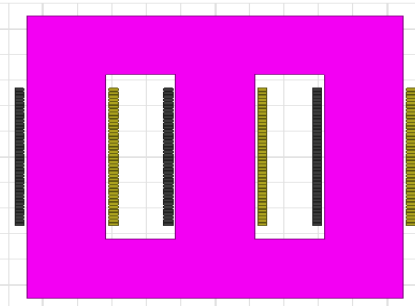

Figure 9: 2-D model of 15 MVA power transformer

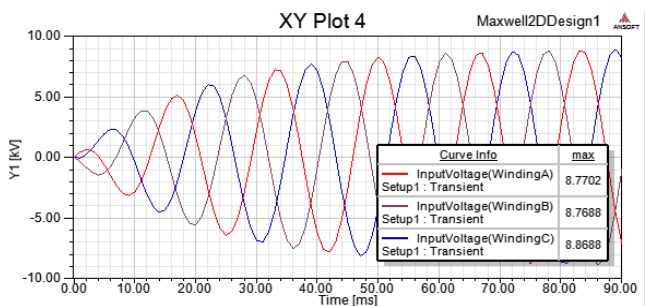

Figure 10: LV winding peak voltage waveform

FIG.11 shows the core loss plot of transformer. Core loss is obtained in watts per meter cube. The volume of core is 1.378 meter cube (calculation is not shown in the paper). So the obtained value of core loss is 9317 watts.

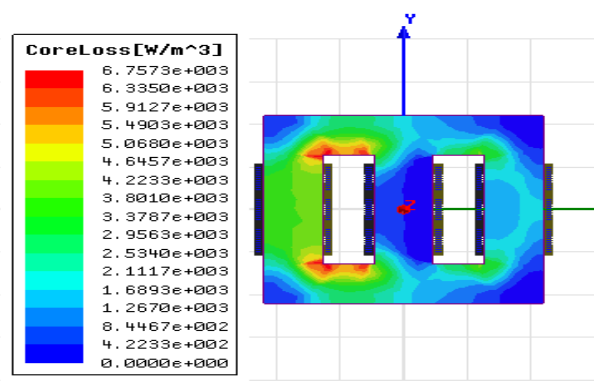

As it can be seen that in

Figure 11: core loss plot of 15 MVA power transformer : meter cube while in 3-D we get exact value or core ıss. so in $2-\mathrm{L}$ simulation we need to muıtıpıy the obtained value with the volume of the core. 


\section{Comparison of results}

The results of core loss obtained by simulating the 15 MVA power transformer in 3-D FEM and 2D FEM are compared in table 2.

\begin{tabular}{|c|c|c|c|}
\hline MODEL & $\begin{array}{c}\text { EXPERIMEN- } \\
\text { TAL VALUE OF } \\
\text { CORE LOSS }\end{array}$ & $\begin{array}{c}\text { OBTAINED } \\
\text { VALUE OF } \\
\text { CORE LOSS }\end{array}$ & $\begin{array}{c}\text { \% VARIATION } \\
\text { FROM } \\
\text { EXPERIME- } \\
\text { NTAL VALUE }\end{array}$ \\
\hline IN 3-D FEM & $9034 \mathrm{~W}$ & $9205.8 \mathrm{~W}$ & $1.9 \%$ \\
\hline IN 2-D FEM & $9034 \mathrm{~W}$ & $9317 \mathrm{~W}$ & $3.1 \%$ \\
\hline
\end{tabular}

Table 2: comparison of results

The above table shows the comparison of core loss value obtained from 3-D FEM and 2-D FEM with the experimental results. The percentage variation of core loss of the transformer modeled in 2-D with respect to experimental value is $3.1 \%$, while the percentage variation of transformer modeled in $3-\mathrm{D}$ is $1.9 \%$. This shows the accuracy of the transformer being modeled in $3-\mathrm{D}$.

\section{Conclusion}

From this paper we conclude that the power transformer simulated in 3-D gives more accurate results as compared to the same transformer simulated in 2-D. The percentage variation of core loss in the transformer simulated in 2-D with respect to experimental value is $3.1 \%$, while that of transformer simulated in 3-D is $1.9 \%$. Also the winding loss was calculated in 3-D FEM. The percentage variation of winding loss with experimental value is $2.8 \%$. Thus, for the accurate analysis of the result, it is important to simulate the 3 -D model of transformer.

\section{References}

[1] Abbaszadeh, K., et al. "Modeling of BH Loop for Core Loss Calculations in Power Transformer Using Finite Element Method." 2006 12th Biennial IEEE Conference on Electromagnetic Field Computation. IEEE.

[2] Constantin, Dorinel, Petre-Marian Nicolae, and Cristina-Maria Nitu. "3D Finite element analysis of a three phase power transformer." EUROCON, 2013 IEEE. IEEE, 2013.

[3] Dlala, Emad. "A simplified iron loss model for laminated magnetic cores." IEEE Transactions on Magnetics 44.11 (2008): 3169-3172.

$\lceil 4\rceil$ Kirar, Mukesh, et al. "Study of stray losses reduction through Finite Element Method." 2013 Annual IEEE India Conference (INDICON). 2013. 